\title{
An EIAV field isolate reveals much higher levels of subtype variability than currently reported for the equine lentivirus family Jodi K Craigo ${ }^{1,2}$, Shannon Barnes ${ }^{1,2}$, Baoshan Zhang ${ }^{1,2}$, Sheila J Cook ${ }^{3}$, Laryssa Howe ${ }^{2}$, Charles J Issel ${ }^{3}$ and Ronald C Montelaro*1,2
} \author{
USA \\ Email: Jodi K Craigo - craigoj@pitt.edu; Shannon Barnes - smd22@pitt.edu; Baoshan Zhang - baz8@pitt.edu; \\ Sheila J Cook - sheila.cook@uky.edu; Laryssa Howe - lhowe@ihug.co.nz; Charles J Issel - cissel@pop.uky.edu; \\ Ronald C Montelaro* - rmont@pitt.edu \\ * Corresponding author
}

Address: ${ }^{1}$ Center for Vaccine Research, University of Pittsburgh, Pittsburgh, PA 15261, USA, ${ }^{2}$ Department of Microbiology and Molecular Genetics, University of Pittsburgh, Pittsburgh, PA 15261, USA and ${ }^{3}$ Department of Veterinary Science, University of Kentucky, Lexington, Kentucky, 40516,

Published: 20 October 2009

Retrovirology 2009, 6:95 doi:10.1/86/1742-4690-6-95

This article is available from: http://www.retrovirology.com/content/6/I/95

(C) 2009 Craigo et al; licensee BioMed Central Ltd.

This is an Open Access article distributed under the terms of the Creative Commons Attribution License (http://creativecommons.org/licenses/by/2.0), which permits unrestricted use, distribution, and reproduction in any medium, provided the original work is properly cited.
Received: 28 July 2009

Accepted: 20 October 2009

\begin{abstract}
Background: Equine infectious anemia virus (EIAV), a lentivirus that infects horses, has been utilized as an animal model for the study of HIV. Furthermore, the disease associated with the equine lentivirus poses a significant challenge to veterinary medicine around the world. As with all lentiviruses, EIAV has been shown to have a high propensity for genomic sequence and antigenic variation, especially in its envelope (Env) proteins. Recent studies have demonstrated Env variation to be a major determinant of vaccine efficacy, emphasizing the importance of defining natural variation among field isolates of EIAV. To date, however, published EIAV sequences have been reported only for cell-adapted strains of virus, predominantly derived from a single primary virus isolate, EIAV Wyoming $_{\text {(EIAV }}$ WY $)$.
\end{abstract}

Results: We present here the first characterization of the Env protein of a natural primary isolate from Pennsylvania $\left(E I A V_{P A}\right)$ since the widely utilized and referenced EIAV ${ }_{W Y}$ strain. The data demonstrated that the level of EIAV $\mathrm{PA}_{\mathrm{PA}}$ Env amino acid sequence variation, approximately $40 \%$ as compared to $E I A V_{W Y}$, is much greater than current perceptions or published reports of natural EIAV variation between field isolates. This variation did not appear to give rise to changes in the predicted secondary structure of the proteins. While the EIAV $\mathrm{PA}_{\mathrm{PA}}$ Env was serologically cross reactive with the Env proteins of the cell-adapted reference strain, EIAV $_{P V}$ (derivative of EIAV ${ }_{W Y}$ ), the two variant Envs were shown to lack any cross neutralization by immune serum from horses infected with the respective virus strains.

Conclusion: Taking into account the significance of serum neutralization to universal vaccine efficacy, these findings are crucial considerations towards successful EIAV vaccine development and the potential inclusion of field isolate Envs in vaccine candidates. 


\section{Background}

Equine Infectious Anemia Virus (EIAV), a macrophagetropic lentivirus of the family Retroviridae, causes a persistent and potentially fatal infection in equids and a chronic disseminated disease that is of worldwide importance in veterinary medicine (reviewed in Craigo, et al. 2008 and Leroux et al. 2004). Natural and experimental infection with EIAV results in a rapid and dynamic disease process that differs markedly from the slowly progressive degenerative diseases associated with other lentiviral infections including HIV-1 infection of humans. EIAV infection can be transmitted via iatrogenic sources such as contaminated syringe needles, but is predominantly spread by blood-feeding insect vectors (mainly horseflies and deerflies). Hence, disease is most problematic in regions with warmer climates [1,2]. The actual number of infected animals in various geographical regions is not precisely known due to a lack of routine testing. Since its inception, testing in the United States has generally increased on an annual basis [3], but the number of animals tested still represents a small proportion of the total equine population.

EIA disease in equids emerges as a vigorous progression through three stages: acute, chronic, and inapparent. The acute and chronic stages of EIA are defined by episodes of clinical disease that are triggered by waves of viremia and distinguished by fever, anemia, thrombocytopenia, edema, diarrhea, lethargy, and various wasting signs. By 812 months post-infection, horses typically progress to lifelong (long-term) inapparent carriers, presumably due to the development of enduring protective host immunity [4]. These inapparent carriers, however, remain infected for life with the maintenance of markedly different levels of steady state virus replication in monocyte-rich tissue reservoirs [5-7]. Stress or immune suppression of EIAV inapparent carriers can induce an increase in viral replication and potentially a recrudescence of disease [7-9]. Thus, EIAV offers a unique model for characterizing natural immunologic control of lentivirus replication and disease, for elucidating the nature and role of viral variation in persistence and pathogenesis, and ultimately for developing and modeling lentiviral vaccines.

Among virulent lentiviruses, EIAV is unique in that greater than $90 \%$ of infected horses progress from a chronic disease state to an inapparent carrier stage despite aggressive virus replication and associated rapid antigenic variation. However, the United States Department of Agriculture (USDA) along with state animal regulatory agencies require euthanasia or strict lifelong quarantine for EIAV seropositive horses. Within the US, each state drafts its own requirements with reference to EIAV and the movement of horses as well as changes in ownership of horses. All seropositive horses must be registered with the state veterinarians and the federal Animal and Plant Health Inspection Service (APHIS) office [3,10]. Given EIAV's role as an animal model for HIV vaccine studies, the associated costs of equine testing, and the general issue of equine health, the development of an effective EIAV vaccine holds a multifaceted significance. Like all lentiviruses, the roadblock to effective vaccine development for EIAV is the high level of antigenic variation that occurs during viral replication throughout all stages of infection and disease.

Studies of EIAV variation during persistent infection in experimentally infected equids have clearly identified characteristic changes in envelope sequences that alter viral antigenic properties, evidently as a result of immune selection [11-14]. The predominant site of EIAV variation during persistent infection is the gp90 surface envelope glycoprotein. The pattern of gp90 nucleotide and amino acid variation has been analyzed to define distinct conserved and variable protein domains [13,15-17] as observed with other animal and human lentiviruses $[13,18-21]$. Variation of the EIAV envelope gene has therefore served as a distinct marker for analysis of viral population evolution and can hence be utilized as a marker of variant isolates.

Despite the worldwide prevalence of EIAV infections, experimental studies to date have centered on relatively few viral isolates. Analyses of viral pathogenesis have essentially focused on a strain of EIAV termed Wyoming (isolated in North America) and its derivatives while a minority of reported studies have utilized a Chinese variant. In fact, in the last thirty years, $97 \%$ of published studies on EIAV natural isolates have been based on the Wyoming isolate directly, or on in vivo/in vitro derivatives of this strain (based on a PubMed search on EIAV natural isolates or experimental derivatives of those isolates within the last 30 years: approximately 548 publications; the percentage of the overall number published for each "strain" was calculated). The variant nature of the antigenicity of EIAV which has thus far obstructed successful vaccine development mandates that a larger pool of viral strains be analyzed both for consideration of pathogenesis and determination of immune correlates of protection.

In the current study, we report on the characterization of the Env genomic sequences of an EIAV field isolate recovered from a long-term inapparent carrier in the state of Pennsylvania in the United States. The observed variation of the EIAV $\mathrm{PA}_{\mathrm{PA}}$ Env compared to published EIAV isolates indicates that the current understanding of genomic divergence is greatly underestimated. Further, functional analyses of how the gp90 variation affected antigenic specificity demonstrated that the observed genomic alterations rendered the isolate neutralization distinct to 
immune sera from horses experimentally infected with a Wyoming-derived virus strain $\left(\operatorname{EIAV}_{\mathrm{PV}}[22-24]\right)$. The observations of extensive Env variation and neutralization differences in a primary EIAV isolate indicate the need for EIAV vaccine strategies that can elicit enduring broadly reactive host immune responses to protect against diverse strains of virus.

\section{Results}

\section{Recovery of a primary EIAV field isolate}

To characterize EIAV viral populations of naturally infected horses, we contacted the local USDA office for information on regionally identified EIAV positive carriers that were under quarantine. They identified a 25 -year-old Coggins positive horse that had been infected for 15 years, but had been clinically inapparent for several years. Analysis of the serum from this donor horse indicated an antibody titer of $10^{4}$ in ELISA assays against the EIAV $V_{\mathrm{PV}}$ reference strain, consistent with the seropositive results also observed in AGID diagnostic assays (data not shown). Quantitative RT-PCR analysis of plasma from the donor horse revealed a viral load in the periphery of approximately $5 \times 10^{3}$ copies of RNA/ml plasma. To characterize the viral population of the field isolate, $\operatorname{EIAV}_{\mathrm{PA}^{\prime}}$ viral RNA was pelleted from the plasma. We designed consensus primers (see additional file 1: Table $\mathrm{S} 1$ ) to reverse transcribe and PCR amplify the $\mathrm{EIAV}_{\mathrm{PA}}$ genome based on currently available sequences in the Genbank repository. RT-PCR amplification of viral RNA failed to yield products for cloning and sequencing. It has previously been demonstrated that a blood transfer performed between an inapparent carrier and an EIAV naïve equine results in febrile EIA disease [7]. We also previously demonstrated that a majority of the viral quasispecies found in the first febrile episode reflect the same genomic sequence as the infectious inoculum [11-13]. Taken together, we chose to characterize the EIAV $_{\mathrm{PA}}$ population of the inapparent carrier via a plasma transfer between the naturally infected animal and an EIAV naïve recipient horse.

Clinical and virological profile of plasma transfer recipient \#9807 An outbred, mixed-breed naïve horse (\#9807) was infected with $\operatorname{EIAV}_{\mathrm{PA}}$ by transfer of infectious plasma ( 5 $\mathrm{ml}$ ) intravenously. The recipient horse was monitored daily for clinical signs of EIA (fever, lethargy, petechiation, diarrhea) and blood samples were taken at regular intervals for measurement of platelets, plasma virus, and EIAVspecific serum antibodies. At approximately 70 DPI the horse experienced an acute clinical EIA episode characterized by concurrent thrombocytopenia and fever accompanied by a viremic episode of $10^{5}$ copies RNA/ml (Fig. 1). Over the course of the observation period (approximately 1.5 years), clinical disease progressed from acute to chronic to inapparent. Over the 550 day observation

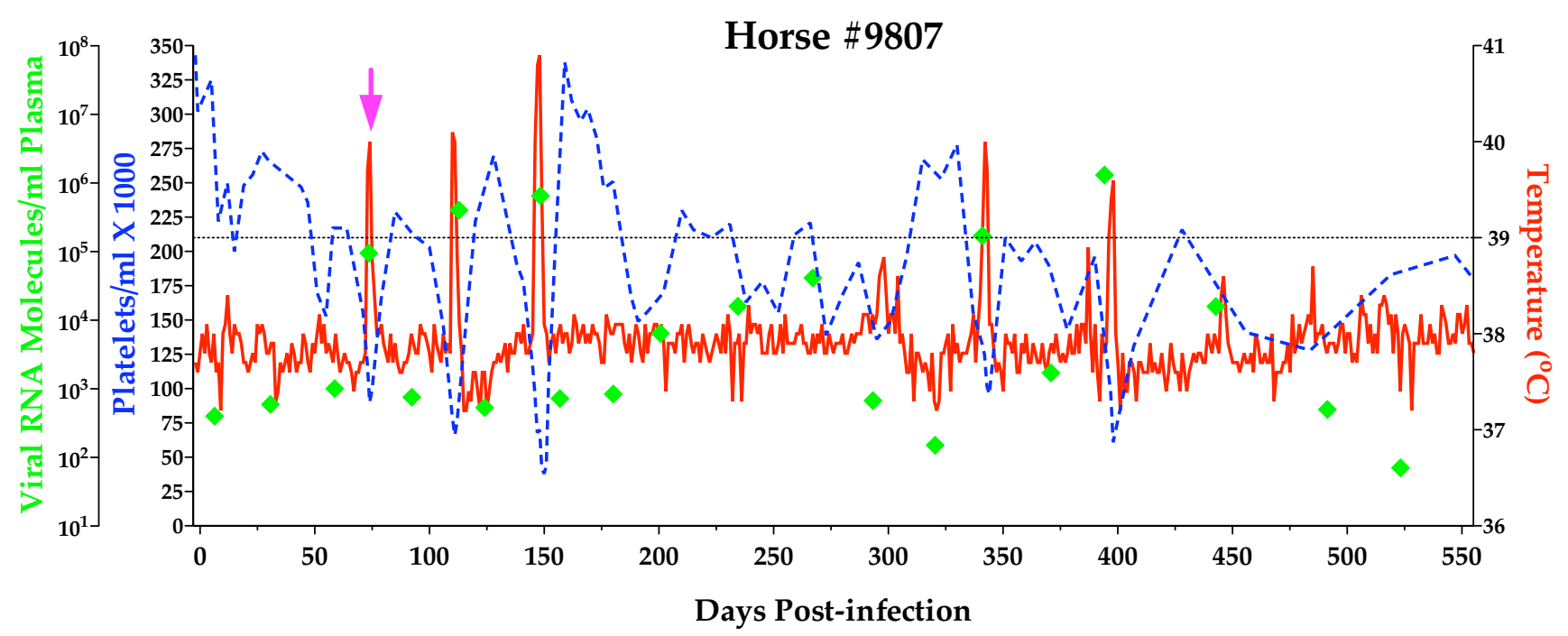

Figure I

Clinical and virological profiles of experimentally infected horse \#9807. Horse \#9807 was experimentally infected

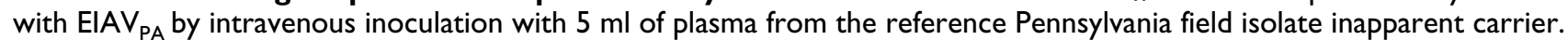
Rectal temperatures (red line, right $Y$ axis) and platelet counts (blue dashed line, Ist left $Y$ axis) were followed daily for approximately 550 days (X-axis). Quantitation of the virus load (green diamond, $2^{\text {nd }}$ left $Y$ axis) was performed on viral RNA extracted from plasma at periodic time points during throughout the initial infection, fever episodes and asymptomatic stages. Febrile episodes were defined by a rectal temperature above $39^{\circ} \mathrm{C}$ in conjunction with a reduction in the number of platelets below 100,000/ $\mu$ l of whole blood and other clinical signs of EIA disease. The acute phase of disease (74DPI) from which viral populations were sampled is indicated (pink arrow). 
period there was a total of five fever episodes. The viral loads exhibited typical fluctuations averaging around $10^{3}$ copies $\mathrm{RNA} / \mathrm{ml}$ plasma in periods of steady state replication and increasing to about $10^{5}-10^{6}$ copies RNA $/ \mathrm{ml}$ plasma during febrile episodes (Fig. 1).

Isolation, cloning, and sequencing of EIAV $V_{P A}$ clones

To characterize the viral quasispecies of $\mathrm{EIAV}_{\mathrm{PA}^{\prime}}$ we isolated viral RNA from plasma taken during the acute episode, or 74 days post infection (DPI), in the recipient horse. The majority of EIAV genomic variation occurs in the 3 ' half of the viral RNA that encodes the envelope, rev, and the long terminal repeat (LTR) $[2,4,7]$. Thus, utilizing the consensus primers described in 3.1, we RT-PCR amplified the entire 3 ' half ( $\sim 3 \mathrm{~Kb})$ of the genome. The purified fragments were cloned, and a total of 18 positive clones subjected to sequence analysis.

\section{Population analyses of EIAV $V_{P A}$ quasispecies}

Our primary goal was to explore natural EIAV diversity that directly affects vaccine development by examining the env gene, specifically the gp90 region. Three other prime regions of relevance, but not of primary significance for vaccine development, namely the env gp 45, S2, and rev genes, as well as the LTR were also sequenced; and the results are included in the additional files 2, 3, 4 and 5. Once nucleotide sequencing was completed, the deduced amino acid sequences were visually inspected to determine the phenotype of the viral quasispecies (Fig. 2 and additional files 2, 3, 4, 5, Figs. S1-S4). Immediately, the primary observation is the vast difference in the EIA$\mathrm{V}_{\mathrm{PA}}$ sequences as compared to the widely utilized Wyoming-derivative EIAV $_{\mathrm{PV}}$ and the published Chinese vaccine strain (Fig. 3). The EIAV $\mathrm{PA}_{\mathrm{PA}}$ Env sequences varied well outside of the currently designated gp90 "variable" regions $[13,15,17]$. Phylogenetic analyses demonstrated that the observed sequence differences between the EIA$\mathrm{V}_{\mathrm{PA}}$ isolates and other known EIAV strains cluster the reported Env populations and the EIAV ${ }_{\mathrm{PA}}$ population into a star phylogeny reminiscent of the clades distinguished in HIV-1 subtypes (Fig. 3). Calculated diversity between a consensus EIAV $_{\mathrm{PA}}$ amino acid sequence and Wyoming gp90 was approximately $40 \%$, compared to the current $13 \%$ maximum reported divergence among published EIAV gp90 sequences from Wyoming- derived and Chinese strains. Variations within the gp90 amino acid residues included the shifting of potential N-linked glycosylation sites among the EIAV $_{\text {PA }}$ quasispecies as compared to the Wyoming-derivative gp90 sequences. Lentiviruses utilize dense glycosylation to shield the envelope proteins from immune recognition. The number of potential glycosylation sites observed in the $\mathrm{EIAV}_{\mathrm{PA}}$ gp90 ranged from 15-21, depending on the individual Env clone. On average there were 19 potential glycosylation sites in the
EIAV $_{\text {PA }}$ gp90, approximately $10 \%$ higher than what is observed with the Wyoming-derivative EIAV species. Notable, however, is the relative conservation of the approximate location of these glycosylation sites among the variant gp90 quasispecies. For example, in the "V3" region the EIAV ${ }_{\mathrm{PA}}$ population maintained three potential $\mathrm{N}$-inked glycosylation sites in all variants, however, the exact location of the sites "shifted" within the respective V3 domains of the variant Env species. As observed previously, there appears to be a complete preservation of all cysteine locations in the $\mathrm{EIAV}_{\mathrm{PA}}$ gp90 compared to published Env sequences despite the marked variation among these gp90 species. This conservation of cysteine residues appears to be indicative of secondary structural conservation, presumably related to their role in disulfide bridges and loop formations within the gp90 protein. Furthermore, comparison of the predicted amino acid sequences determined for the gp45, Rev, and S2 proteins also reveals a conservation of critical structural features despite the substantial variation in protein sequences and high levels of average divergence (gp45, 44\%, Rev, 39\%, S2, 54\%) from the Wyoming strain (additional files 3, 4, 5, Figs. S2S4). For example, in gp45 all extracellular potential Nlinked glycosylation sites are maintained between species although the amino acid make-up of the site may vary. Similarly, in spite of the significant differences in the amino acid sequence of EIAV $\mathrm{PA}_{\text {PA }}$ Rev compared to published Rev sequences, the published RNA binding domain and nuclear export signals of Rev are conserved in EIAV $\mathrm{PA}_{\text {. }}$

\section{Characterization of EIAV $V_{P A}$ envelope antigenic properties}

To characterize the effects of the observed EIAV $_{\text {PA }}$ gp90 variation on antigenic properties of the Env protein, we next evaluated the Env-specific serum antibody responses of horse \#9807 utilizing two separate methods, end point titer analyses (heterologous) and neutralization (homologous and heterologous) assays. We have previously characterized a complex and lengthy maturation of immune responses to viral envelope proteins during the first six to eight months post-infection that appears to be a distinctive feature of lentiviral infections as steady state infection and host immunity levels are established [25-28]. The serum of the inapparent carrier cross-reacted in ELISA with the Env proteins of our reference strain EIAV $_{\mathrm{PV}}$ as demonstrated in earlier analyses (c.f. section 3.1). Hence, we initially characterized the development of serum antibodies in horse \#9807 by longitudinal analyses of serum end-point titers to the Env protein of the reference strain EIAV $_{\mathrm{PV}}$. The evolution of the end-point titer of EIAV-specific serum antibodies demonstrated a characteristic development of a mature response that gradually increased throughout the first 6 months of infection, at which time the end point titer reach a steady state of approximately $10^{4}$ (Fig. 4A). 

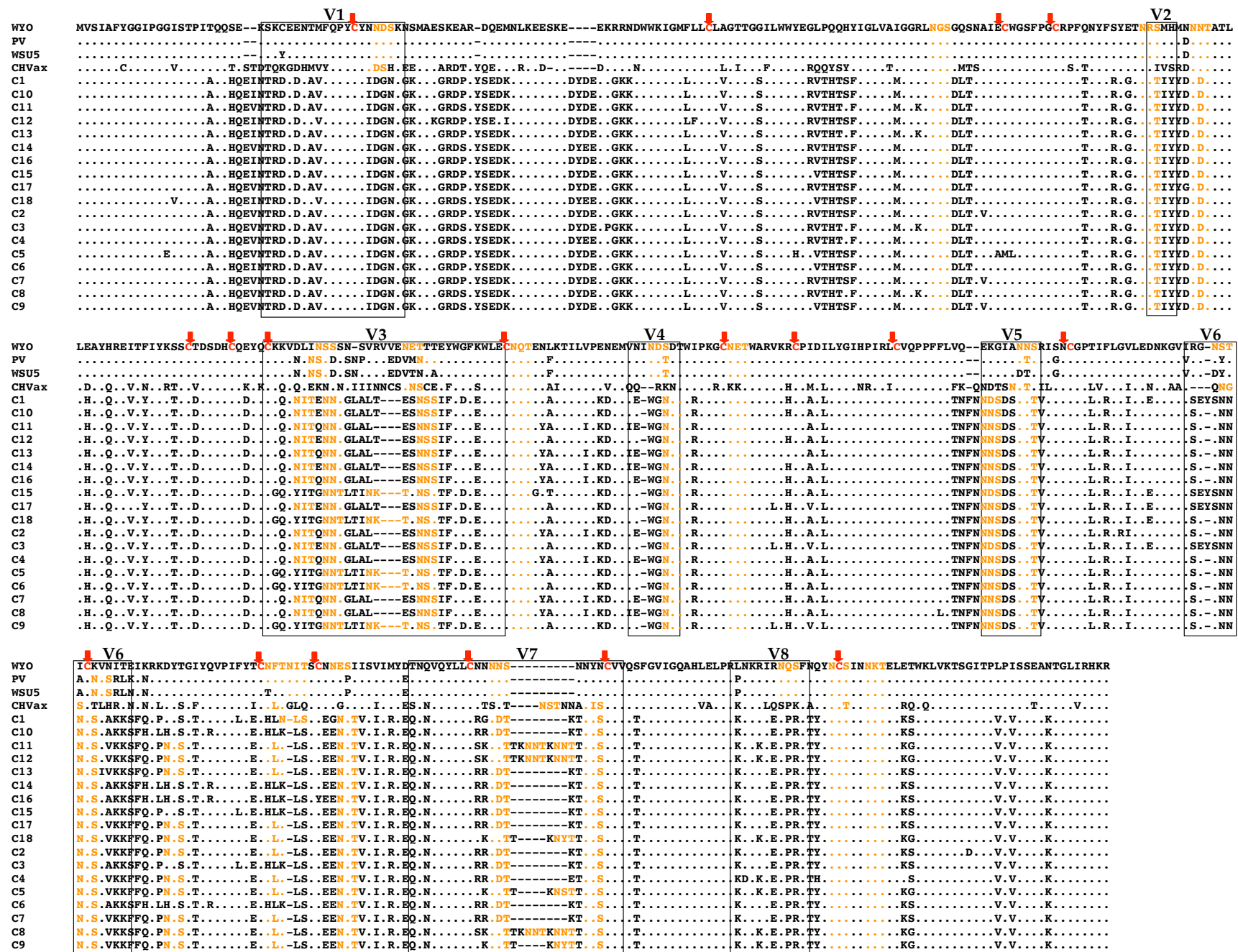

\section{Figure 2}

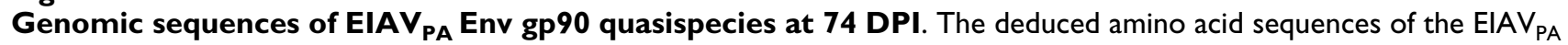
population and reference EIAV sequences were aligned in ClustalW to the EIAV Wyoming strain. Residues that are different from Wyoming are indicated by their single amino acid designations. Reported variable regions for the gp 90 sequence are boxed. Residues identical to Wyoming sequence are indicated with (black circle). Glycosylation sites are colored orange. WYO, Wyoming; PV, EIAV ${ }_{\mathrm{PV}}$; CHVax, Chinese vaccine stain; black line, absent residue; black arrow, Cysteine residues.

We have reported a moderately slow development of serum neutralizing antibodies over a several month period following experimental EIAV infection of horses, with average maximum neutralization titers averaging $1: 300[5,27]$. To examine the ability of the $\operatorname{EIAV}_{\mathrm{PA}}$ strain to elicit homologous and heterologous serum neutralizing antibodies, we assayed the ability of serum samples taken from horse \#9807 (428 DPI) and the original Pennsylvanian inapparent carrier (two months post transfer to \#9807) to neutralize $\operatorname{EIAV}_{\mathrm{PA}}$ and $\mathrm{EIAV}_{\mathrm{PV}}$ gp90 species, as presented on otherwise common proviral constructs (Fig. $4 \mathrm{~B})$. The neutralization activity of a reference immune serum taken from a horse experimentally infected with
$\operatorname{EIAV}_{\text {PV }}(1,574$ DPI) was assayed in parallel as a control. Interestingly, immune sera from the experimentally EIA$\mathrm{V}_{\mathrm{PA}}$ and the EIAV $\mathrm{PV}_{\mathrm{PV}}$ infected horses were able to neutralize only virus containing the homologous virus gp90; there was no detectable neutralization of the virus containing the heterologous gp90 species. In contrast, however, the immune serum from the naturally infected inapparent carrier displayed neutralization activity against both the $\operatorname{EIAV}_{\text {PA }}$ (1:200 titer) and $\operatorname{EIAV}_{\text {PV }}$ (1:55 titer) gp90 Env species. Two-way ANOVA analyses of the neutralization results indicate a significant difference between the ability of the inapparent carrier serum to neutralize the two different gp90 Env proteins $(P<0.0001)$. 


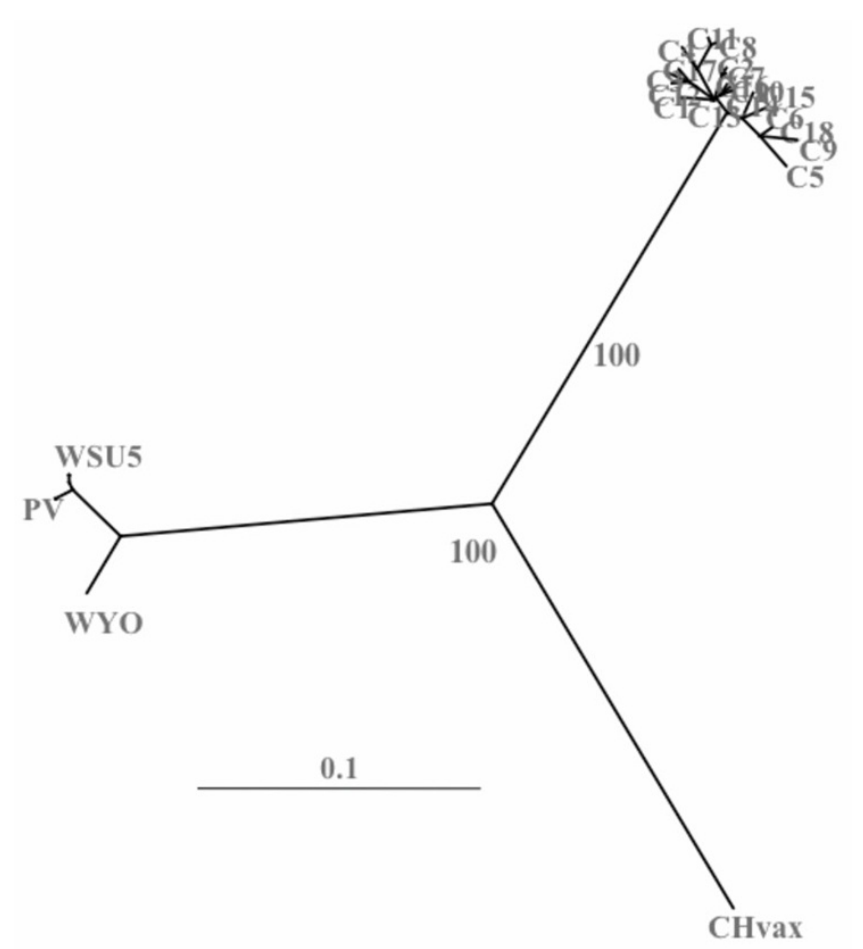

Figure 3

Population characterization of horse \#9807 viral envelope gp90 sequences. A phylogenetic tree of aligned deduced amino acid sequences was constructed by the neighbor joining method from Kimura corrected distances with the optimality criterion set to distance. The tree was unrooted. Bootstrap values were determined over 1000 iterations and are indicated at the nodes of the branches. Branch lengths are proportional to the distance existing between the sequences. C"\#", EIAV $\mathrm{PA}_{\text {A }}$ clone number; WYO, Wyoming; $\mathrm{PV}, \mathrm{EIAV}_{\mathrm{PV}} ; \mathrm{CHVax}$, Chinese vaccine stain.

\section{Discussion}

EIAV in addition to being an animal model for HIV/AIDS studies is a potentially fatal and economically significant infectious disease of equines found in populations of horses worldwide. We have thoroughly explored the evolution of Wyoming-derivative EIAV strains [11-14,29-35] and investigated in detail EIAV interactions with the immune system $[5,28,36]$ as well as mechanisms of protection towards the development of a vaccine [28,36-43]. Vaccine development is essential to the global control of EIA. A common problem to all lentiviral vaccine development is the obstacle of viral evolution and more specifically viral Envelope variation and diversity.

To address this problem of Env variation and vaccine efficacy, it is essential to develop a more detailed characterization of the natural level of variation in the primary protein conferring vaccine protection, gp90. The overall level of envelope divergence observed for other common lentiviruses such as the small ruminant lentiviruses (SRLV), FIV, SIV and HIV have averaged between 10-35\% [44-51]. Present understanding of the variation of EIAV has been based on a very limited number of natural field isolates. The current study of the $\mathrm{EIAV}_{\mathrm{PA}}$ isolate represents the first characterization of the Env protein of a natural primary isolate. The data reveal a much greater extent of Env variation than previously deduced from published Env sequences from a limited number of reference viral strains, all cell-adapted. The observed variation of the EIA$\mathrm{V}_{\mathrm{PA}}$ inapparent carrier population was very similar to what we have recognized in inapparent carriers from experimental infections. The level of diversity was at the same average level (data not shown) and the included phenotypic changes of a similar nature to previously observed evolution in experimental infections. While the largest amount of variation previously reported among published Env sequences indicated a maximum divergence of up to $13 \%$ variation $[11,12]$, the $\operatorname{EIAV}_{\mathrm{PA}}$ gp90 sequence reveals a divergence of about $40 \%$ from EIAV $_{\mathrm{PV}}$ and other published Env sequences. In addition to the presumed effects of this extent of Env variation on vaccine development, it is important to note that the $\operatorname{EIAV}_{\mathrm{PA}}$ gp90 sequence is derived from a primary virus isolate that has never been passaged in cell culture. Thus it may be assumed that the EIAV ${ }_{\mathrm{PA}}$ Env species may in fact be more representative of natural Env populations than the currently published Env species that are derived from virus isolated by cell culture. In this regard, the $\operatorname{EIAV}_{\mathrm{PA}}$ may be considered a better candidate for vaccine development compared to other cell adapted strains of EIAV.

Recently we published a report detailing the specific affects of envelope sequence variation on vaccine protection [42]. In that study we identified for the first time a significant, inverse, linear correlation between vaccine efficacy and increasing divergence of the challenge virus gp90 compared to the vaccine virus gp90 protein. The vaccine study demonstrated approximately $100 \%$ protection of immunized horses from disease after challenge by virus with a homologous gp90, but only 50\% protection against challenge by virus with an Env that was 13\% divergent from the vaccine strain. The calculated linear relationship predicted a complete lack of protection of immunized horses from disease upon challenge with a virus gp90 that is $23 \%$ divergent from the vaccine strain. Thus, these data suggest that the $40 \%$ divergence observed with the EIAV $V_{\text {PA }}$ strain would present a substantial obstacle to the development of a broadly protective vaccine against EIA.

The extensive divergence observed between the EIAV $\mathrm{PA}_{\mathrm{PA}}$ and EIAV $_{\mathrm{PV}}$ Env would predict differences in immunogenicity and antigenicity, including neutralization sensitivity. The current data indeed indicated distinct 

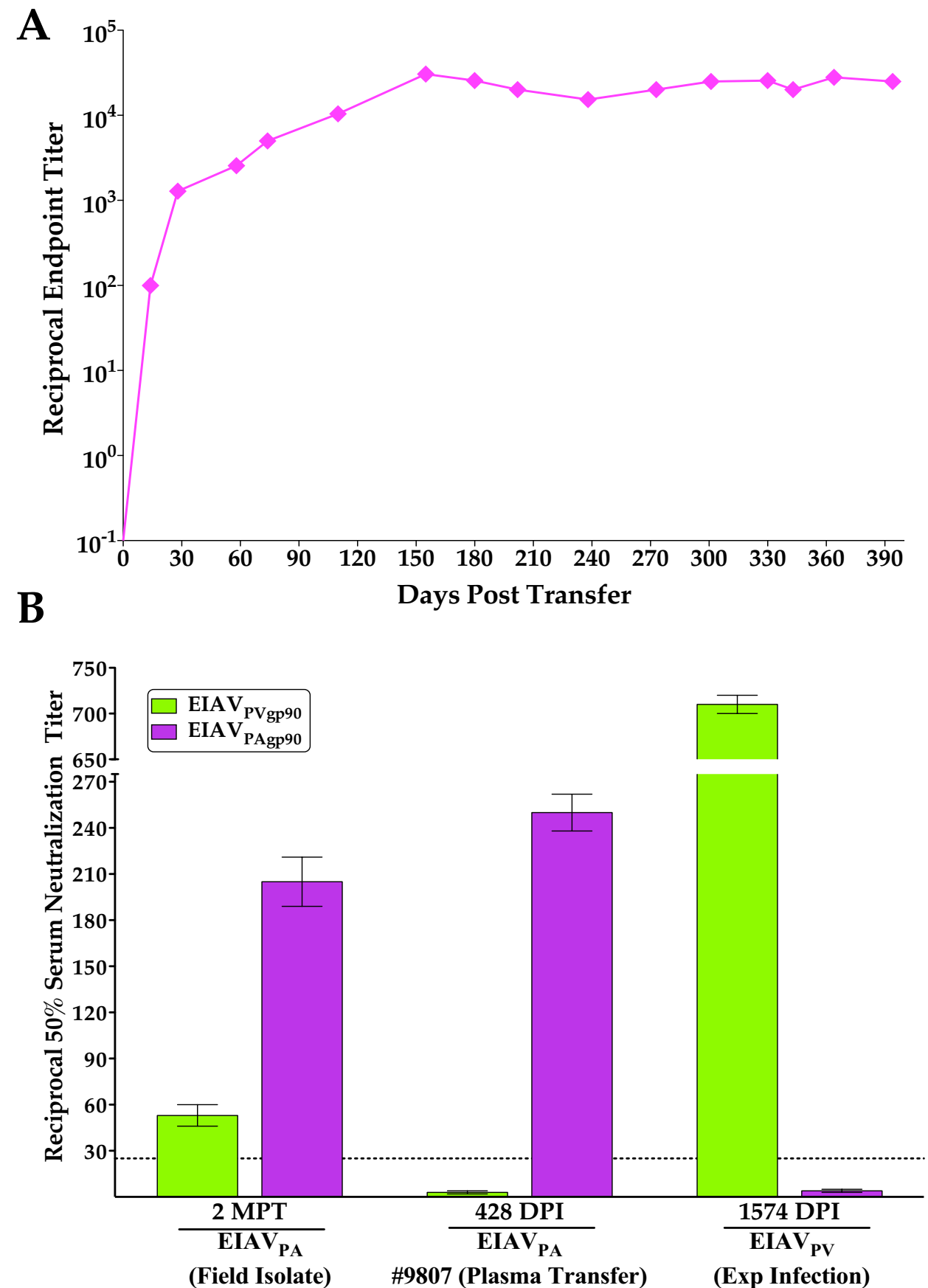

Figure 4

Characterization of the Env reactivity of serum antibodies elicited by EIAV $\mathrm{PA}_{\mathrm{PA}}$ inection of horse 9807 . Envelopespecific reactivities were analyzed in both an (A) end-point titer assay and a (B) neutralization assay. (A) Longitudinal characterization of the quantitative properties of induced EIAV envelope-specific antibodies were conducted in ConA ELISA assay utilizing $\mathrm{EIAV}_{\mathrm{PV}}$ as the antigen. Mean serum antibody titers for each time point are presented as the $\log _{10}$ of the highest reciprocal dilution yielding reactivity two standard deviations above background. (B) The mean reciprocal dilutions of serum from infected horses that neutralized $50 \%$ of input EIAV $\mathrm{PV}_{\mathrm{PV}}$ or EIAV $\mathrm{PA}_{\mathrm{PP}} 90$ as measured in an infectious center assay. Serum samples included: EIAV $\mathrm{PA}^{-}$serum from the original Pennsylvanian field isolate plasma donor and serum from the recipient pony \#9807, $E_{I A V_{P V}}$ serum from an experimentally infected long-term inapparent carrier. The line (dashed black line) denotes the cut off ( $\geq$ 25 ) value for valid $50 \%$ neutralization titers. MPT, months post transfer; DPI, days post infection. 
neutralization specificities for the two variant Env species. However, the current immune assays also indicated a substantial amount of cross reactive serum antibody as measured by ELISA assays, indicating common antibody epitopes in the variant Env proteins, despite the $40 \%$ divergence in gp90 amino acid sequences (Fig. 4A). Why this antibody cross-reactivity did not confer neutralization of variant infectious viruses remains to be determined by more rigorous characterization of the neutralization epitopes of the Env protein and the effects of sequence variation on antibody binding to and inactivation of virions.

It is of interest to note that only the immune serum from the long-term inapparent carrier displayed significant neutralization activity against both the $\mathrm{EIAV}_{\mathrm{PA}}$ and $\mathrm{EIAV}_{\mathrm{PV}}$ Env species (Fig. 4B). Since this immune serum reflects at least 25 years of persistent EIAV infection, it is possible that the broad neutralization activity is due to a maturation of antibody responses to constantly changing EIAV populations with variant Env quasispecies over this time period. While the mechanism of this cross neutralization is uncertain, it may be attributed to the collection of antibody responses to immuno-dominant type specific variable domains of the viral gp90 protein or alternatively to the slowly progressive development of antibody to immuno-recessive conserved domains of gp90. Experimental differentiation between these alternative mechanisms will provide important fundamental information relevant to the design of optimal Env protein for vaccine development.

\section{Conclusion}

The ability of the immune serum from the long-term inapparent carrier to ultimately neutralize viruses expressing either the EIAV ${ }_{\mathrm{PV}}$ and $\mathrm{EIAV}_{\mathrm{PA}}$ gP90 protein species indicates that it is possible for the horse immune system to develop broadly neutralizing serum antibodies. Based on this observation, it will now be possible to experimentally identify the specific Env sequences that are reactive with cross-neutralizing antibodies and that may be used in vaccines to develop enduring broadly reactive antibody responses. Whether we can incorporate this new EIAV $_{\mathrm{PA}}$ sequence information into an immunogen that can confer the level of protection observed in long-term infected animals such as the Pennsylvania animal is the challenge to vaccine development and remains to be seen. What is definite is that additional field isolates need to be evaluated in order to develop EIAV vaccines that have a chance of being broadly protective to EIAV infection.

\section{Methods}

\section{Identification of a natural EIAV inapparent carrier}

The USDA local office (Allegheny County, Pennsylvania) identified a naturally infected, clinically inapparent, EIAV- positive horse. The horse had been EIAV seropositive for approximately 15 years at the time of sampling, as determined by repeated serum testing in the present USDA reference AGID diagnostic assay [52]. Per Pennsylvania statutes and regulations, the horse was maintained in isolation and was under the surveillance of the local USDA Office with annual EIAV retesting. Under the supervision of the local USDA veterinarian, $500 \mathrm{ml}$ of whole blood was drawn from this inapparent carrier by venipuncture into an ACD vacuum bottle. Peripheral blood mononuclear cells (PBMCs), plasma, and sera were collected and stored as previously described [13].

\section{Attaining an EIAV field isolate}

Initial attempts to amplify and clone EIAV from the plasma of the inapparent carrier yielded insufficient levels of viral genomic PCR products (data not shown), probably due to a very low level of viremia at the time of isolation [12]. We have previously demonstrated that the viral population associated with the initial febrile episode in an experimentally infected horse fundamentally represents the species present in the infectious inoculum [11-13] and provides a much higher viral level to obtain samples for analysis. Thus, we transferred plasma from the inapparent carrier to a naïve recipient horse to amplify the viral quasispecies for subsequent isolation and characterization.

\section{Experimental infection of naive horses}

An outbred, mixed-breed naïve horse (\#9807) was infected with the Pennsylvanian EIAV (EIAV ${ }_{\mathrm{PA}}$ ) field isolate by transferring $5 \mathrm{ml}$ of infectious plasma from the identified naturally infected donor animal. The animal was monitored daily and maintained as described previously $[13,14]$. Platelet numbers were determined using the Unopette microcollection system (Becton Dickinson, Rutherford, N.J.). Clinical EIA (fever) episodes were determined on the basis of rectal temperature and platelet count in combination (rectal temperature $>39^{\circ} \mathrm{C}$; platelet number $<100,000 / \mu \mathrm{l}$ of whole blood) with the presence of infectious plasma virus $[2,7,13,14]$. Samples of whole blood, serum, and plasma were collected weekly and daily during fever episodes. Plasma samples were stored at $80^{\circ} \mathrm{C}$ until used to determine plasma viral RNA level and to perform genetic analysis of viral RNA. Serum samples were stored at $-20^{\circ} \mathrm{C}$ until being tested for antibody reactivity.

\section{Field isolate viral RNA purification and amplification}

Viral RNA was extracted as described previously $[12,13,41]$ from plasma taken during the acute disease episode in the recipient horse at 74 DPI. Reverse transcription of 2 to $5 \mu$ of purified viral RNA was performed with the SuperScriptII PreAmplification System (GibcoBRL, Rockville, MD) as previously described [13]. Multiple nested amplifications of the 3 ' half of the genome were 
performed as reported [13] using the Elongase mix (Gibco BRL, Rockville, MD). Primers for primary and nested amplifications are detailed in additional file 1, Table S1. PCR products were visualized on a $1 \%$ agarose gel prior to purification and cloning.

\section{Quantitative Viral RNA determinations}

Plasma samples were analyzed for the levels of viral RNA per milliliter of plasma using a previously described quantitative real-time multiplex RT-PCR assay based on gagspecific amplification primers [53]. The standard RNA curve was linear in the range of $10^{1}$ molecules as a lower limit and $10^{8}$ molecules as an upper limit.

\section{Cloning and Sequencing}

Several independent RT-PCR products (3 independent RT reactions and 8 independent nested PCR reactions) were generated (refer to 2.2.2), gel-purified using Qiagen's Qiaex (Valencia, CA), and cloned individually into the pCR2.1-TOPO ${ }^{\circledast}$ vector (Invitrogen, Carlsbad, CA). Individual clones were screened by PCR. Positive colonies were consequently grown, plasmid DNA was extracted, and clones automatically sequenced (Applied Biosystems, Foster City, CA) using internal EIAV primers (see additional file 1, Table S1). DNA sequences were resolved with an ABI Prism 373 DNA sequencer (Applied Biosystems, Foster City, CA).

\section{Sequence Analysis}

Sequences were assembled and error checked using GeneJockey II (Biosoft, Cambridge, UK). Nucleotide and deduced amino acid sequences from each clone were aligned using the ClustalW multiple sequence alignment program from the GCG Wisconsin software package and edited manually when necessary. Alignments were performed for each genomic region with the reference strains: Wyoming, Wyoming derivative strains EIAV $_{\mathrm{PV}}$ and EIAV $_{\text {WSU5, }}$ and the Chinese vaccine strain. The amino acid divergence calculations were determined using the Kimura distance correction.

Distance analyses were conducted using Distance software as implemented in the GCG Wisconsin software package [54]. Phylogenetic analyses of sequences were constructed by the neighbor-joining method with the optimality criterion set to distance as measured in PAUP [55]. Statistical significance of branchings and clustering were assessed by bootstrap re-sampling of 1000 pseudoreplicates on the complete data set represented in a 75\% majority-rule consensus tree. The tree was edited for presentation using Treeview68 K version 1.5.

\section{Nucleotide Sequences}

All sequences have been submitted to GenBank. Nucleotide accession numbers are GBQ855742-GBQ855758.

\section{Construction and production of EIAV $V_{\text {PAgp90 }}$}

To compare the neutralization properties of the EIAV $V_{P A}$ envelope to those of the $\mathrm{EIAV}_{\mathrm{PV}}$, we generated a chimeric clone in which the gp90 of the representative predominant EIAV ${ }_{\mathrm{PA}}$ clone (associated with the first disease cycle) was substituted into the proviral backbone of our reference $\mathrm{EIAV}_{\mathrm{UK} 3}$ molecular clone [56] utilizing standard molecular biology techniques [57]. Briefly, the gp90 gene of clone 2 from the PA field isolates derived from horse \#9807 was digested with PasI and BtsI. The purified digestion product was ligated into the $\mathrm{EIAV}_{\mathrm{UK} 3}$ backbone, which had also been digested with BtsI and Pas I (partial digestion with PasI). Clones were screened by sequencing using internal EIAV primers. Chimeric virus (EIAV ${ }_{\text {PAgp } 90)}$ was produced by transfecting a $4-\mu$ g sample of purified DNA from the chimeric proviral clone into $10^{5}$ fetal equine kidney (FEK) cells as specified by the manufacturer of the GenePorter Transfection kit (GTS, San Diego, Calif.). The number of infectious units per $\mathrm{ml}$ of supernatants from transfected FEK cell cultures was then determined in a standardized infectious-center assay that uses a cell-based enzyme-linked immunosorbent assay detection system to study FEK cells [58].

\section{Serological Analyses}

Detection of serum antibody reactivity to the EIAV capsid protein p26 was conducted using the ViraCHEK ${ }^{\circledast} /$ EIA kit per the manufacturer's instructions (Synbiotics Laboratory, Via Frontera, San Diego, CA). Serum samples were also evaluated for seroreactivity by the standard Coggins AGID diagnostic assay for EIA. Serum IgG antibody reactivity to EIAV envelope glycoproteins was assayed quantitatively (end point titer) using our standard concanavalin A (ConA) ELISA procedures [27]. Virus neutralizing activity to EIAV $_{\mathrm{PV}}$ [22-24] and EIAV $\mathrm{PA}_{\mathrm{PA} 90}$ (refer to 2.6) mediated by immune sera was assessed in an indirect cellELISA based infectious center assay using a constant amount of infectious virus and sequential 2-fold dilutions of serum $[27,58]$. Statistical significance was calculated using GraphPad software (GraphPad software Inc., LaJolla, CA.).

\section{Competing interests}

The authors declare that they have no competing interests.

\section{Authors' contributions}

JKC participated in the design and directing of the study; isolated, cloned and analyzed the sequence of the viral strains; performed immunoassays and drafted the manuscript. SB performed the viral load analyses, serology and immunoassays. BZ constructed the chimeric virus clones for the immunoassays. SJC performed all procedures on the animals as well as the daily observations on the subjects. LH performed DNA isolations and provided assistance with sequencing and blood collection from field 
animal. CJI directed the animal studies. RCM conceived and participated in the design of the study and helped to draft the manuscript. All authors read and approved the final manuscript.

\section{Additional material}

\section{Additional File 1}

Table S1. This file is a table depicting the primers used to amplify and sequence the primary isolate.

Click here for file

[http://www.biomedcentral.com/content/supplementary/17424690-6-95-S1.PDF]

\section{Additional File 2}

Figure S1. Genomic sequence of EIAV $V_{P A}$ LTR population. The nucleotide sequences of the EIAV $V_{P A}$ population and reference EIAV sequences were aligned in ClustalW to the EIAV Wyoming strain. Residues that are different from Wyoming are indicated. Transcription factor recognition sequences are boxed. Bases identical to Wyoming sequence are indicated with (white square). WYO, Wyoming; PV, EIAV $V_{P V}$; CHVax, Chinese vaccine stain; white square, absent base.

Click here for file

[http://www.biomedcentral.com/content/supplementary/17424690-6-95-S2.PDF]

\section{Additional File 3}

Figure S2. Genomic sequence of $E I A V_{P A} S 2$ population. The deduced amino acid sequences of the EIAV $V_{P A}$ population and reference EIAV sequences were aligned in ClustalW to the EIAV Wyoming strain. Residues that are different from Wyoming are indicated by their single amino acid designations. Reported predicted nucleoporin motif, SH3 binding motif, and nuclear localization signal are underlined in the Wyoming strain. Residues identical to Wyoming sequence are indicated with (white square). Predicted N-myristilation signal is in red text and boxed. Predicted CK2 phosphorylation site is in pink text and boxed. PKC phosphorylation sites are in blue text and boxes. Predicted $\beta$-sheet is indicated with (white arrow) and boxed in orange. Predicted alpha helix is indicated with (white cylinder) and boxed in yellow. All structural predictions were performed using PredictProtein http://www.predictprotein.org/. WYO, Wyoming; PV, EIAV $V_{P V}$ CHVax, Chinese vaccine stain; white square, absent residue.

Click here for file

[http://www.biomedcentral.com/content/supplementary/17424690-6-95-S3.PDF]

\section{Additional File 4}

Figure S3. Genomic sequence of EIAV $V_{P A}$ Rev second exon population The deduced amino acid sequences of the EIA $V_{P A}$ population and reference EIAV sequences were aligned in ClustalW to the EIAV Wyoming strain. Residues that are different from Wyoming are indicated by their single amino acid designations. Reported activation domain, RNA binding site and nuclear exportation signal are underlined in the Wyoming sequence and are boxed in the EIAV $V_{P A}$ population and reference EIAV sequences. Residues identical to Wyoming sequence are indicated with (white square). Glycosylation sites are colored orange. WYO, Wyoming; $P V, E I A V_{P V} ; C H V a x$, Chinese vaccine stain; white square, absent residue. Click here for file

[http://www.biomedcentral.com/content/supplementary/17424690-6-95-S4.PDF]

\section{Additional File 5}

Figure S4. Genomic sequence of EIAV $V_{P A}$ Env gp45 population. The deduced amino acid sequences of the EIAV $V_{P A}$ population and reference EIAV sequences were aligned in ClustalW to the EIAV Wyoming strain. Residues that are different from Wyoming are indicated by their single amino acid designations. The transmembrane domain is boxed. Residues identical to Wyoming sequence are indicated with (white square). Glycosylation sites are colored orange. WYO, Wyoming; PV, EIAV $V_{P V}$ CHVax, Chinese vaccine stain; white square, absent residue.

Click here for file

[http://www.biomedcentral.com/content/supplementary/17424690-6-95-S5.PDF]

\section{Acknowledgements}

We thank John Cardamone for his excellent technical assistance in DNA sequencing. The authors would also like to thank Jonathan D. Steckbeck for editing the manuscript. This work was supported by the National Institutes of Health grant number ROI AI 25850, by funds from the Lucille P. Markey Charitable Trust and the Kentucky Agricultural Experimental Station, and by a grant from the Pittsburgh Supercomputing Center through the NIH National Center for Research Resources, resource grant 2 P4I RR06009.

\section{References}

I. Issel C], Foil LD: Studies on equine infectious anemia virus transmission by insects. J Am Vet Med Assoc 1984, 184:293-297.

2. Leroux C, Cadore JL, Montelaro RC: Equine Infectious Anemia Virus (EIAV): what has HIV's country cousin got to tell us? Vet Res 2004, 35:485-5I2.

3. APHIS: Equine Infectious Anemia (EIA). (USDA ed.: Veternairy Services) 2006.

4. Craigo JK, Montelaro RC: Equine Infectious Anemia Virus (Retroviridae). In Encyclopedia of Virology Volume 2. Third edition. Academic Press; 2008:167-I74. [Mahy BW], Regenmortel MHVv (Series Editor)

5. Hammond SA, Li F, McKeon BM Sr, Cook SJ, Issel CJ, Montelaro RC: Immune responses and viral replication in long-term inapparent carrier ponies inoculated with equine infectious anemia virus. I Virol 2000, 74:5968-598I.

6. Harrold SM, Cook SJ, Cook RF, Rushlow KE, Issel CJ, Montelaro RC: Tissue sites of persistent infection and active replication of equine infectious anemia virus during acute disease and asymptomatic infection in experimentally infected equids. J Virol 2000, 74:3||2-3|2|.

7. Montelaro RC, Ball JM, Rushlow K: Equine retroviruses. In The Retroviridae Volume 2. Edited by: Levy JA. New York, N.Y.: Plenum Press; 1993:257-360.

8. Craigo JK, Leroux C, Howe L, Steckbeck JD, Cook SJ, Issel CJ, Montelaro RC: Transient immune suppression of inapparent carriers infected with a principal neutralizing domain-deficient equine infectious anaemia virus induces neutralizing antibodies and lowers steady-state virus replication. Journal of General Virology 2002, 83: I353-I359.

9. Kono $Y$, hirasawa K, Fukunaga $Y$, Taniguchi $T$ : Recrudesence of equine infectious anemia by treatment with immunosuppressive drugs. Nat Inst Anim Hlth Quart 1976, 16:8-15.

10. APHIS: Equine Infectious Anemia. (USDA ed.: Veternairy Services) 2003.

II. Craigo JK, Sturgeon TJ, Cook SJ, Issel CJ, Leroux C, Montelaro RC: Apparent elimination of EIAV ancestral species in a longterm inapparent carrier. Virology 2006, 344:340-353.

12. Leroux C, Craigo JK, Issel CJ, Montelaro RC: Equine infectious anemia virus genomic evolution in progressor and nonprogressor ponies. J Virol 200I, 75:4570-4583.

13. Leroux C, Issel C, Montelaro RC: Novel and dynamic evolution of equine infectious anemia virus genomic quasispecies asso- 
ciated with sequential disease cycles in an experimentally infected pony. J Virol 1997, 71:9627-9639.

14. Lichtenstein DL, Issel C], Montelaro RC: Genomic quasispecies associated with the initiation of infection and disease in ponies experimentally infected with equine infectious anemia virus. J Virol 1996, 70:3346-3354

I5. Zheng YH, Nakaya T, Sentsui H, Kameoka M, Kishi M, Hagiwara K, takahashi $\mathrm{H}$, Kono $\mathrm{Y}$, Ikuta $\mathrm{K}$ : Insertions, duplications and substitutions in restricted gp90 regions of equine infectious anemia virus during febrile episodes in an experimentally infected horse. Journal of General Virology 1997, 78:807-820.

16. Zheng $\mathrm{YH}$, Sentsui H, Kono Y, Ikuta K: Mutations occurring during serial passage of Japanese equine infectious anemia virus in primary horse macrophages. Virus Res 2000, 68(1):93-98.

17. Zheng $\mathrm{YH}$, Sentsui $\mathrm{H}$, Nakaya $\mathrm{T}$, Kono $\mathrm{Y}$, Ikuta $\mathrm{K}$ : In vivo dynamics of equine infectious anemia viruses emerging during febrile episodes: insertions/duplications at the principal neutralizing domain. J Virol 1997, 71:5031-5039.

18. Greene WK, Meers J, del Fierro G, Carnegie PR, Robinson WF: Extensive sequence variation of feline immunodeficiency virus env genes in isolates from naturally infected cats. Arch Virol 1993, I33:51-62.

19. Suarez DL, Whetstone CA: Identification of hypervariable and conserved regions in the surface envelope gene in the bovine lentivirus. Virology 1995, 21 2:728-733.

20. Starcich ES, Hahn BH, Shaw GM, McNeely PD, Modrow S, Wolf H, Parks ES, Parks WP, Josephs SF, Gallo RC: Identification and characterization of conserved and variable regions in the envelope gene of HTLV-III/LAV, the retrovirus of AIDS. Cell I986, 45:637-648.

21. Simmonds P, Balfe P, Ludlam J, Bishop O, Brown AJ: Analysis of sequence diversity in hypervariable regions of the external glycoprotein of human immunodeficiency virus type I. J Virol 1990, 64:5840-5850.

22. Issel CJ, Horohov DW, Lea DF, Adams WV Jr, Hagius SD, McManus JM, Allison AC, Montelaro RC: Efficacy of inactivated wholevirus and subunit vaccines in preventing infection and disease caused by equine infectious anemia virus. J Virol 1992, 66:3398-3408.

23. Payne SL, Rausch J, Rushlow K, Montelaro RC, Issel C, Flaherty M Perry S, Sellon D, Fuller F: Characterization of infectious molecular clones of equine infectious anaemia virus. J Gen Virol 1994 75(Pt 2):425-429.

24. Rwambo PM, Issel CJ, Adams WV Jr, Hussain KA, Miller M, Montelaro RC: Equine infectious anemia virus (EIAV) humoral responses of recipient ponies and antigenic variation during persistent infection. Arch Virol 1990, I I I:199-2 I2.

25. Cole KS, Murphey-Corb M, Narayan O, Joag SV, Shaw GM, Montelaro RC: Common Themes of Antibody Maturation to Simian Immunodeficiency Virus, Simian-Human Immunodeficiency Virus, and Human Immunodeficiency Virus Type I†Infections. J Virol 1998, 72:7852-7859.

26. Cole KS, Rowles JL, Jagerski BA, Murphey-Corb M, Unangst T, Clements JE, Robinson J, Wyand MS, Desrosiers RC, Montelaro RC: Evolution of envelope-specific antibody responses in monkeys experimentally infected or immunized with simian immunodeficiency virus and its association with the development of protective immunity. J Virol 1997, 7 1:5069-5079.

27. Hammond SA, Cook SJ, Lichtenstein DL, Issel C], Montelaro RC: Maturation of the cellular and humoral immune responses to persistent infection in horses by equine infectious anemia virus is a complex and lengthy process. J Virol 1997, 7 I:3840-3852

28. Montelaro RC, Cole KS, Hammond SA: Maturation of immune responses to lentivirus infection: implications for AIDS vaccine development. AIDS Res Hum Retroviruses I998, I4(SuppI 3):S255-S259.

29. Salinovich O, Payne SL, Montelaro RC, Hussain KA, Issel CJ, Schnorr $\mathrm{KL}$ : Rapid emergence of novel antigenic and genetic variants of equine infectious anemia virus during persistent infection. J Virol 1986, 57:71-80

30. Payne SL, Fang FD, Liu CP, Dhruva BR, Rwambo P, Issel C], Montelaro $R C$ : Antigenic variation and lentivirus persistence: variations in envelope gene sequences during EIAV infection resemble changes reported for sequential isolates of HIV. Virology 1987, | 61:32|-33|.
31. Payne SL, Salinovich O, Nauman SM, Issel C], Montelaro RC: Course and extent of variation of equine infectious anemia virus during parallel persistent infections. J Virol 1987, 6 I: I 266-I270.

32. Payne SL, Rushlow K, Dhruva BR, Issel CJ, Montelaro RC: Localization of conserved and variable antigenic domains of equine infectious anemia virus envelope glycoproteins using recombinant env-encoded protein fragments produced in Escherichia coli. Virology 1989, I 72:609-6I5.

33. Lichtenstein DL, Rushlow KE, Cook RF, Raabe ML, Swardson CJ, Kociba GJ, Issel CJ, Montelaro RC: Replication in vitro and in vivo of an equine infectious anemia virus mutant deficient in dUTPase activity. J Virol 1995, 69:288I-2888.

34. Lichtenstein DL, Craigo JK, Leroux C, Rushlow KE, Cook RF, Cook SJ, Issel C], Montelaro RC: Effects of long terminal repeat sequence variation on equine infectious anemia virus replication in vitro and in vivo. Virology 1999, 263:408-417.

35. Reis JKP, Craigo JK, Cook SJ, Issel CJ, Montelaro RC: Characterization of EIAV LTR variability and compartmentalization in various reservoir tissues of long-term inapparent carrier ponies. Virology 2003, 3 I I: I69- I80.

36. Hammond SA, Raabe ML, Issel C], Montelaro RC: Evaluation of antibody parameters as potential correlates of protection or enhancement by experimental vaccines to equine infectious anemia virus. Virology 1999, 262:416-430.

37. Hammond SA, Cook SJ, Falo LD Jr, Issel CJ, Montelaro RC: A particulate viral protein vaccine reduces viral load and delays progression to disease in immunized ponies challenged with equine infectious anemia virus. Virology 1999, 254:37-49.

38. Li F, Craigo JK, Howe L, Steckbeck JD, Cook S, Issel C, Montelaro RC: A Live Attenuated Equine Infectious Anemia Virus Proviral Vaccine with a Modified S2 Gene Provides Protection from Detectable Infection by Intravenous Virulent Virus Challenge of Experimentally Inoculated Horses. Jf Virol 2003, 77:7244-7253.

39. Craigo JK, Li F, Steckbeck JD, Durkin S, Howe L, Cook SJ, Issel C, Montelaro RC: Discerning an Effective Balance between Equine Infectious Anemia Virus Attenuation and Vaccine Efficacy. J Virol 2005, 79:2666-2677.

40. Tagmyer TL, Craigo JK, Cook SJ, Issel CJ, Montelaro RC: Envelopespecific T-helper and cytotoxic T-lymphocyte responses associated with protective immunity to equine infectious anemia virus. I Gen Virol 2007, 88: | 324- I336.

4I. Craigo JK, Durkin S, Sturgeon TJ, Tagmyer T, Cook SJ, Issel CJ, Montelaro RC: Immune suppression of challenged vaccinates as a rigorous assessment of sterile protection by lentiviral vaccines. Vaccine 2007, 25:834-845.

42. Craigo JK, Zhang B, Barnes S, Tagmyer TL, Cook SJ, Issel CJ, Montelaro RC: Envelope variation as a primary determinant of lentiviral vaccine efficacy. Proceedings of the National Academy of Sciences 2007, 104:15105-15110.

43. Tagmyer TL, Craigo JK, Cook SJ, Even DL, Issel CJ, Montelaro RC: Envelope determinants of equine infectious anemia virus vaccine protection and the effects of sequence variation on immune recognition. J Virol 2008, 82:4052-4063.

44. Burns DP, Collignon C, Desrosiers RC: Simian immunodeficiency virus mutants resistant to serum neutralization arise during persistent infection of rhesus monkeys. JVirol 1993, 67:4I04-4II3.

45. Moore JP, Parren PWHI, Burton DR: Genetic Subtypes, Humoral Immunity, and Human Immunodeficiency Virus Type I Vaccine Development. The Journal of Virology 200 I, 75:572 l-5729.

46. Levy JA: HIV pathogenesis: knowledge gained after two decades of research. Adv Dent Res 2006, I9:10-16.

47. Pisoni G, Quasso A, Moroni P: Phylogenetic analysis of smallruminant lentivirus subtype $B I$ in mixed flocks: evidence for natural transmission from goats to sheep. Virology 2005 , 339:147-152.

48. Shah C, Bni Jr, Huder JB, Vogt H-R, Mhlherr J, Zanoni R, Miserez R, Lutz H, Schupbach J: Phylogenetic analysis and reclassification of caprine and ovine lentiviruses based on 104 new isolates: evidence for regular sheep-to-goat transmission and worldwide propagation through livestock trade. Virology 2004, 3 | 9:12-26.

49. Zanoni RG: Phylogenetic analysis of small ruminant lentiviruses. J Gen Virol 1998, 79(Pt 8): |951-1961. 
50. Brander C, Frahm N, Walker BD: The challenges of host and viral diversity in HIV vaccine design. Curr Opin Immunol 2006, 18:430-437.

5I. Elder JH, Sundstrom M, de Rozieres S, de Parseval A, Grant CK, Lin Y-C: Molecular mechanisms of FIV infection. Veterinary Immunology and Immunopathology 2008, I 23:3-13.

52. Coggins L, Norcross NL: Immunodiffusion reaction in equine infectious anemia. Cornell Vet 1970, 60:330-335.

53. Cook RF, Cook SJ, Li FL, Montelaro RC, Issel C]: Development of a multiplex real-time reverse transcriptase-polymerase chain reaction for equine infectious anemia virus (EIAV). J Virol Methods 2002, 105:17|-179.

54. Group GC: Program manual for the Wisconsin Package. Madison, Wis: Genetics Computer Group; 1994.

55. Swofford DL: PAUP: Phylogenetic Analysis Using Parsimony and Other Methods. Sunderlan, MA: Sinauer Associates; $200 \mathrm{I}$.

56. Cook RF, Cook SJ, Berger SL, Leroux C, Ghabrial NN, Gantz M, Bolin PS, Mousel MR, Montelaro RC, Issel CJ: Enhancement of equine infectious anemia virus virulence by identification and removal of suboptimal nucleotides. Virology 2003, 3 I3:588-603.

57. Maniatis T, Fritsch EF, Sambrook JE: Molecular cloning: a laboratory manual Cold Spring Harbor, N.Y.: Cold Spring Harbor Laboratory; 1982.

58. Grund CH, Lechman ER, Pezzuolo NA, Issel CJ, Montelaro RC: Fine specificity of equine infectious anaemia virus gp90-specific antibodies associated with protective and enhancing immune responses in experimentally infected and immunized ponies. J Gen Virol 1996, 77(Pt 3):435-442.

Publish with Bio Med Central and every scientist can read your work free of charge

"BioMed Central will be the most significant development for disseminating the results of biomedical research in our lifetime. "

Sir Paul Nurse, Cancer Research UK

Your research papers will be:

- available free of charge to the entire biomedical community

- peer reviewed and published immediately upon acceptance

- cited in PubMed and archived on PubMed Central

- yours - you keep the copyright

Submit your manuscript here:

http://www.biomedcentral.com/info/publishing_adv.asp
BioMedcentral 